\title{
C\&RE-SLC: Database for Conservation and Renewable Energy Activities
}

by J.D. Cavalio, M.M. Tompkins, and A.G. Fisher

Policy and Economic Analysis Group,

Environmental Assessment and Information Sciences Division,

Argonne National Laboratory, 9700 South Cass Avenue, Argonne, Illinois 60439

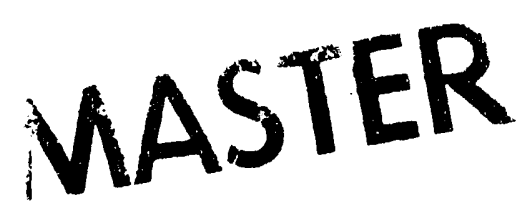

August 1992

Work sponsored by United States Department of Energy, Western Area Power Administration

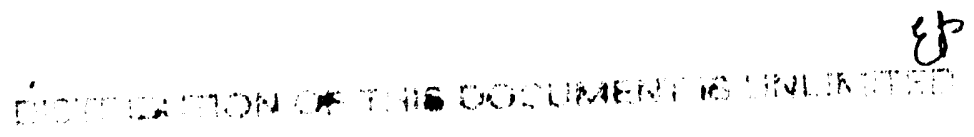




\section{CONTENTS}

ACKNOWLEDGMENTS $\ldots \ldots \ldots \ldots \ldots \ldots \ldots \ldots \ldots \ldots \ldots \ldots$ iv

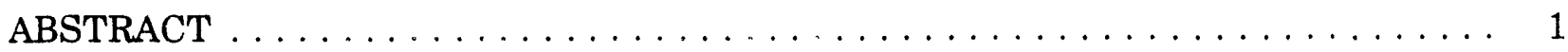

1 INTRODUCTION AND BACKGROUND $\ldots \ldots \ldots \ldots \ldots \ldots \ldots$

2 STRUCTURE AND USE OF THE DATABASE $\ldots \ldots \ldots \ldots \ldots$

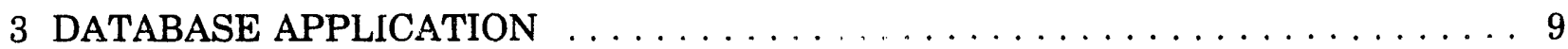

4 AREAS FOR FURTHER RESEARCH $\ldots \ldots \ldots \ldots \ldots \ldots \ldots \ldots \ldots \ldots$

\section{TABLES}

1 Structure of C\&RE-SLC $\ldots \ldots \ldots \ldots \ldots \ldots \ldots \ldots \ldots \ldots \ldots$

$2 \mathrm{G} \& \mathrm{AC}$ Customer C\&RE Activity List $\ldots \ldots \ldots \ldots \ldots \ldots \ldots$

3 Frequency Distribution by Major Activity Type $\ldots \ldots \ldots \ldots \ldots \ldots$ 


\section{ACKNOWLEDGMENTS}

The authors would like to acknowledge the work of Nancy Collins, under whose capable direction the database was initially organized.

The authors would also like to thank Craig Hibberd and Clayton Palmer of Western Area Power Administration for comments and suggestions on an early draft of this report. Appreciation is extended to Florence Henning for editing this document and to Joyce Henry and Maisie Plut for document processing services. 


\title{
C\&RE-SLC: DATABASE FOR \\ CONSERVATION AND RENEWABLE ENERGY ACTIVITIES
}

by

\author{
J.D. Cavallo, M.M. Tompkins, and A.G. Fisher
}

\begin{abstract}
The Western Area Power Administration (Western) requires all its long-term power customers to implement programs that promote the conservation of electric energy or facilitate the use of renewable energy resources. The hope is that these measures could significantly reduce the amount of environmental damage associated with electricity production. As part of preparing the environmental impact statement for Western's Electric Power Marketing Program, Argonne National Laboratory constructed a database of the conservation and renewable energy activities in which Western's Salt Lake City customers are involved. The database provides information on types of conservation and renewable energy activities and allows for comparisons of activities being conducted at different utilities in the Salt Lake City region. Sorting the database allows Western's Salt Lake City customers to be classified so the various activities offered by different classes of utilities can be identified; for example, comparisons can be made between municipal utilities and cooperatives or between large and small customers. The information included in the database was collected from customer planning documents in the files of Western's Salt Lake City office.
\end{abstract}

\section{INTRODUCTION AND BACKGROUND}

In recent years, electric utilities across the country have extended their capability of providing reliable and low-cost service to energy end-users by developing energy conservation programs and exploring the applicability of renewable energy technologies. Approximately 500 utilities are currently sponsoring more than 1,300 demand-side management programs. A majority of states require utilicies to formulate periodic integrated resource plans that incorporate demand-side options like energy conservi.tion and peak-load management whenever their costs are lower than those of supply-side options. Renewable energy technologies also are being explored anew because of increased funding from the federal government. Western Area Power Administration (Western) has been a part of this trend through its program of conservation and renewable energy (C\&RE) activities.

The commitment of Western to the C\&RE program derives from Western's objective of providing reliable electric service while protecting the environment and optimizing energy 
efficiency. Western requires all long-term firm power customers to implement certain activities that will promote the conservation of electric energy or facilitate the use of renewable energy resources. This requirement has existed since 1981 as part of the Guidelines and Acceptance Criteria (G\&AC) published in the Federal Register on November 13, 1981 (46 FR 56140). The G\&AC was amended in 1985 (50 FR 33892), after legislation reinforcing the C\&RE program was passed as part of Title II of the Hoover Power Plant Act. Customers that do not comply with the G\&AC are subject to a penalty - a $10 \%$ reduction in the Western power-contract commitment.

Estimates of the impact that Western's C\&RE programs have had on the power needs of its customers have not been made yet. Nevertheless, some people strongly believe that conservation and alternative energy resources could significantly reduce the need of Western's customers for electricity from both Western and other supply sources. This belief was expressed in scoping meetings held in late 1990 for an environmental impact statement (EIS) on Western's Electric Power Marketing Program for the Salt Lake City Area Integrated Projects (SLCA/IP). Furthermore, some participants in the scoping meetings contended that the aggressive use of peak-load management, energy conservation, and other renewable energy activities would significantly reduce the environmental dannage associated with dam operations.

The Electric Power Marketing Program EIS will include an analysis of the effects that Western's alternatives could have on its customers' C\&RE plans. As part of the analysis, Argonne National Laboratory (ANL) has constructed a database of the C\&RE activities that Western's SLCA customers have introduced.

Although the focus of the ANL effort is directed toward the analysis of impacts to current C\&RE activities from the EIS alternatives, opportunities exist for the C\&RE-SLC database to be used by Western, its customers, and other researchers. The database provides information on types of C\&RE activities and allows for comparisons of activities being conducted at different utilities. Sorting the database allows Western's Salt Lake City customers to be classified so the various activities offered by different classes of utilities can be identified; for example, comparisons can be made between municipal utilities and cooperatives or between large and small customers.

The information included in the database was collected from customer planning documents in the files of Western's Salt Lake City office. Each of Western's customers is required to submit an update to its $C \& R E$ plan every two years. Customers also are required to determine goals for each of their C\&RE activities and to evaluate their success in meeting these goals. The announcement in the Federal Register (50 FR 33897) states that Western cannot approve a customer program that offers a low energy savings and that customers must commit resources and develop a reasonable organizational strategy to demonstrate a good faith effort to reach the stated goals. 


\section{STRUCTURE AND USE OF THE DATABASE*}

The C\&RE-SLC database has been developed on an IBM-compatible personal computer through use of the FoxPro database program. This database can be used in the FoxPro program or in another compatible database program that can access DBF files. The computer file is quite large and requires approximately 2 megabytes of disk storage space. To allow for transfer to potential users, the file is compressed by using the PKZIP computer shareware program. The diskette on which the compressed version of the database is provided also contains a copy of the PKUNZIP shareware program. The database can be decompressed by copying both the PKUNZIP program and the compressed database (CRESLC.ZIP) to a subdirectory on an IBM-compatible PC. The database user would then type PKUNZIP CRESLC.ZIP and Enter. This operation results in a database file named CRESLC.DBF. The FoxPro (or other database program) manuals offer details concerning the operation of the database program software.

The C\&RE-SLC database was organized to accurately represent the information included in the planning documents submitted by Western customers. For accurate representation, the database follows the same structure as the program files found at Western's Salt Lake City offices. The structure of the database is given in Table 1. The most important parts of the database are the identification of activity types, the specification of the goal that each utility has for its activities, and the description of the activities. Various other items in the database permit sorting of the activities so that relevant combinations of database records can be searched, combined, or examined for research and analysis.

Each record in the database represents an activity included in a planning-year submittal from one of Western's Salt Lake City customers. The records have been given a unique record number (Rec_num) for identification purposes. The record numbers were initially sequential, but the sequence has been altered as records have been dropped as a result of duplication or correction. To facilitate the sorting of the many customers in the database, each record includes the customer name (Util_name) and an identification number (Util_id) for the customer. The database contains records from 109 Western customers. Each customer may have from one to four separate planning-year submittals. As many as 15 separate activities can be described within each planning year.

The Input_by field is included in the database for purposes of quality control. Users of the database need not be concerned with this field.

The submittal year of the plan to which the activity is connected is given in the Plan_year field. The C\&RE plans are proposed every three to four years, and a C\&RE program verification is submitted every two years. Both the proposal and the verification consist of multiple activities and thus are represented in several records in the database.

\footnotetext{
${ }^{*}$ Throughout the text of this report, italics are used to indicate computer commands and field names.
} 
TABLE 1 Structure of C\&RE-SLC

\begin{tabular}{cllr}
\hline $\begin{array}{c}\text { Item } \\
\text { Number }\end{array}$ & $\begin{array}{c}\text { Field } \\
\text { Title }\end{array}$ & \multicolumn{1}{c}{ Item } & $\begin{array}{c}\text { Length } \\
\text { (bytes) }\end{array}$ \\
\hline 1 & Rec_num & A unique data record identification number & 4 \\
2 & Util_id & An identification number for each utility & 3 \\
3 & Util_name & The name of the utility & 20 \\
4 & Input_by & The name of the individual entering the record & 8 \\
5 & Plan_year & The plan year corresponding to the record & 4 \\
6 & Act_code & An identification number for the activity type & 4 \\
7 & Requirmt & M for mandatory; V for voluntary & 2 \\
8 & Activity & The type of activity & 80 \\
9 & Goal & The utility's goal for the activity & 200 \\
10 & Status & An activity may be ongoing, new, or complete & 100 \\
11 & Desc_1 & A description of the activity & 200 \\
12 & Desc_2 & A continuation of Desc_1 & 200 \\
13 & Desc_3 & A continuation of Desc_1 & 200 \\
14 & Desc_4 & A continuation of Desc_1 & 200 \\
15 & Desc_5 & A continuation of Desc_1 & 200 \\
16 & Desc_6 & A continuation of Desc_1 & 200 \\
17 & Util_type & The type of utility (Muni, Coop, etc.) & 6 \\
18 & Wapa_assn & The system within which the utility belongs & 10 \\
19 & GWh_sold & The GWh sales by Western to the utility & 8 \\
20 & Init_plan & The year of the first plan submitted to Western & 4 \\
21 & Mand_act & The number of mandatory activities & 2 \\
22 & Vol_act & The number of voluntary activities & 2 \\
\hline
\end{tabular}

Because an activity tends to appear in several plans, the Plan_year field can be used to distinguish between an activity's initial proposal and that same activity's continuing evaluation and evolution.

Each activity is categorized by type. The codes for the activities were established in the G\&AC for the C\&RE program (50 FR 33892) in 1985. The codes denote the specific activities that Western's customers can select to fulfill their C\&RE requirement. The codes, which are included in the database under the field name Act_code, are given in Table 2. Each code has an initial letter identifying its category. After the category letter, either a number or a number and a succeeding letter indicate a specific activity within the category. For example, category $F$ contains all activiti ? that improve production efficiency, and activity $F 1$ is an activity that increases production efficiency by improving generation equipment.

Some customers have included as many as 15 C\&RE activities in a planning-year submittal. A customer can institute an unlimited number of C\&RE activities, as long as a required minimal number of activities is reached. The number of activities required by each utility is determined by the amount of energy sold to that utility by Western. The schedule that determines the number of activities required is determined by the sales per year in gigawatt-hours; for 0-49 sales, 3 activities are required; for 50-99, 4 are required; and for 100 or more, 5 are required. Each activity in the database is marked either $M$ for mandatory or 
TABLE 2 G\&AC Customer C\&RE Activity List

\begin{tabular}{l}
$\begin{array}{c}\text { Code } \\
\text { Activity }\end{array}$ Activity Name \\
\hline Category A - Energy Consumption Efficiency Improvements
\end{tabular}

A1 Building energy-conservation programs, which may include activities such as:

A1a Boiler, furnace, air conditioner retrofitting, including dual fuel

A1b Weatherization/insulation

Alc Storm windows/doors

A1d Insulation of air ducts, boilers, pipes, etc.

Ale Heat-reflective/absorbing window or floor materials, waterheaters, etc.

A1f Clock thermostats and equipment/system timers

Alg Electrical or mechanical ignition systems

A1h Heat pumps

A2 Energy audits

A3 Installation of energy-storage equipment, thermal energy storage

A4 Information dissemination programs

A5 Economic assessment studies for conservation activities

A6 Development of energy efficiency awards programs

A7 Building plan review/service programs

A8 Loan arrangements or assistance

A9 Conservation demonstration projects

A10 Installation arrangements/assistance

A11 Attendance at conservation and/or renewable energy training

A12 Technical assistance to end-users

A13 Listing services for suppliers/lenders

A14 Customer in-house program activities

A15 Use of infrared-heat-detection equipment

A16 Home energy-rating systems development

A17 Computer programs development for conservation/energy efficiencies or community energy-management strategies

A18 Energy-efficient lighting conversions

A19 Equipment inspection programs

A20 Improvement of operating procedures to maximize efficiencies

A21 Building code requirements

A22 Use of blower doors

Category B - Renewable Energy Activities

B1 Solar thermal/photovoltaic projects

B2 Solar pond projects

B3 Daylighting technologies

B4 Active solar installations

B5 Ocean thermal gradients/tidal power

B6 Passive solar installations

B7 Small//arge-scale wind turbine installations

B8 Biomass/refuse-derived fuels (RDF) projects

B9 Geothermal projects 
TABLE 2 (Cont.)

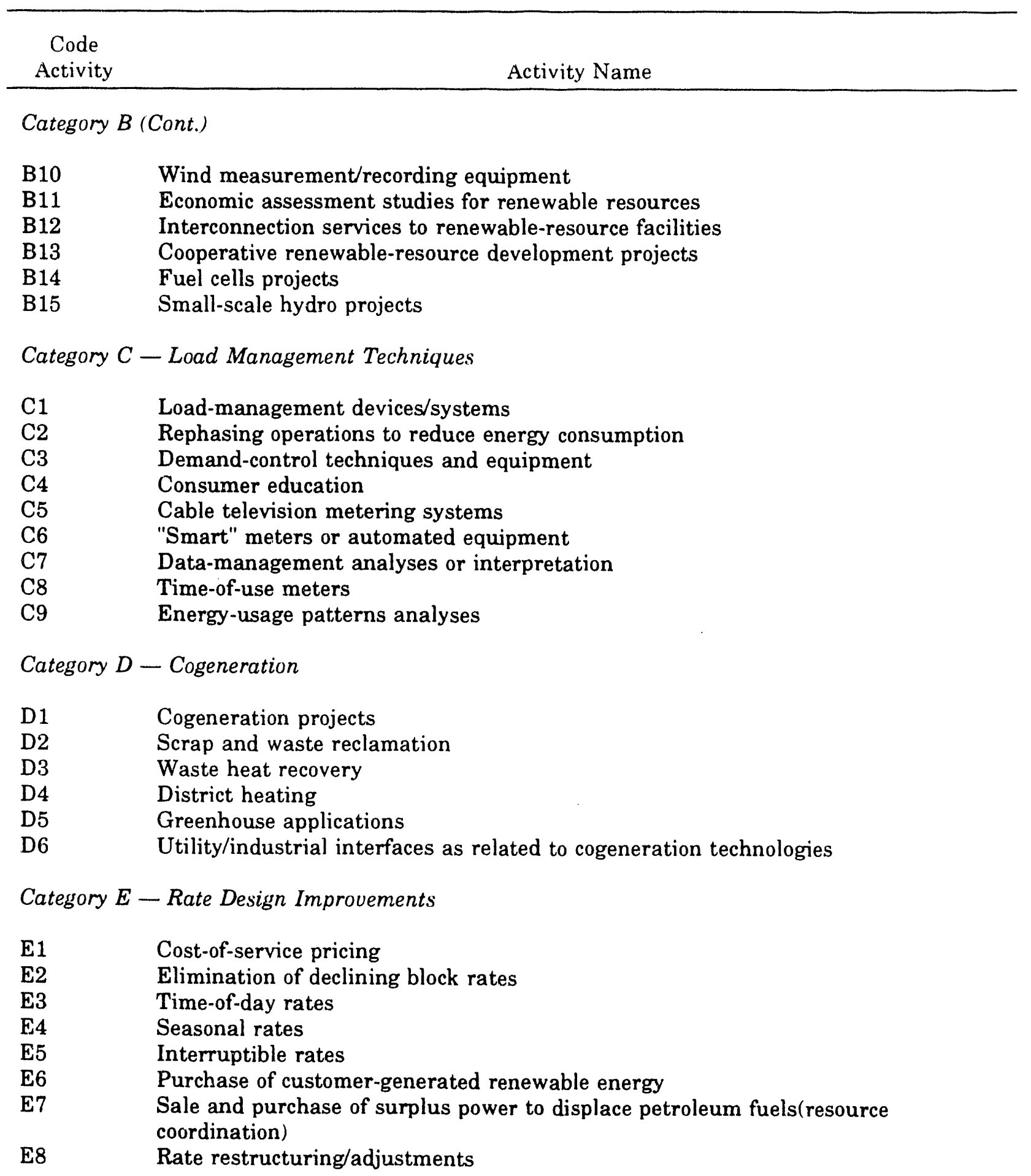


TABLE 2 (Cont.)

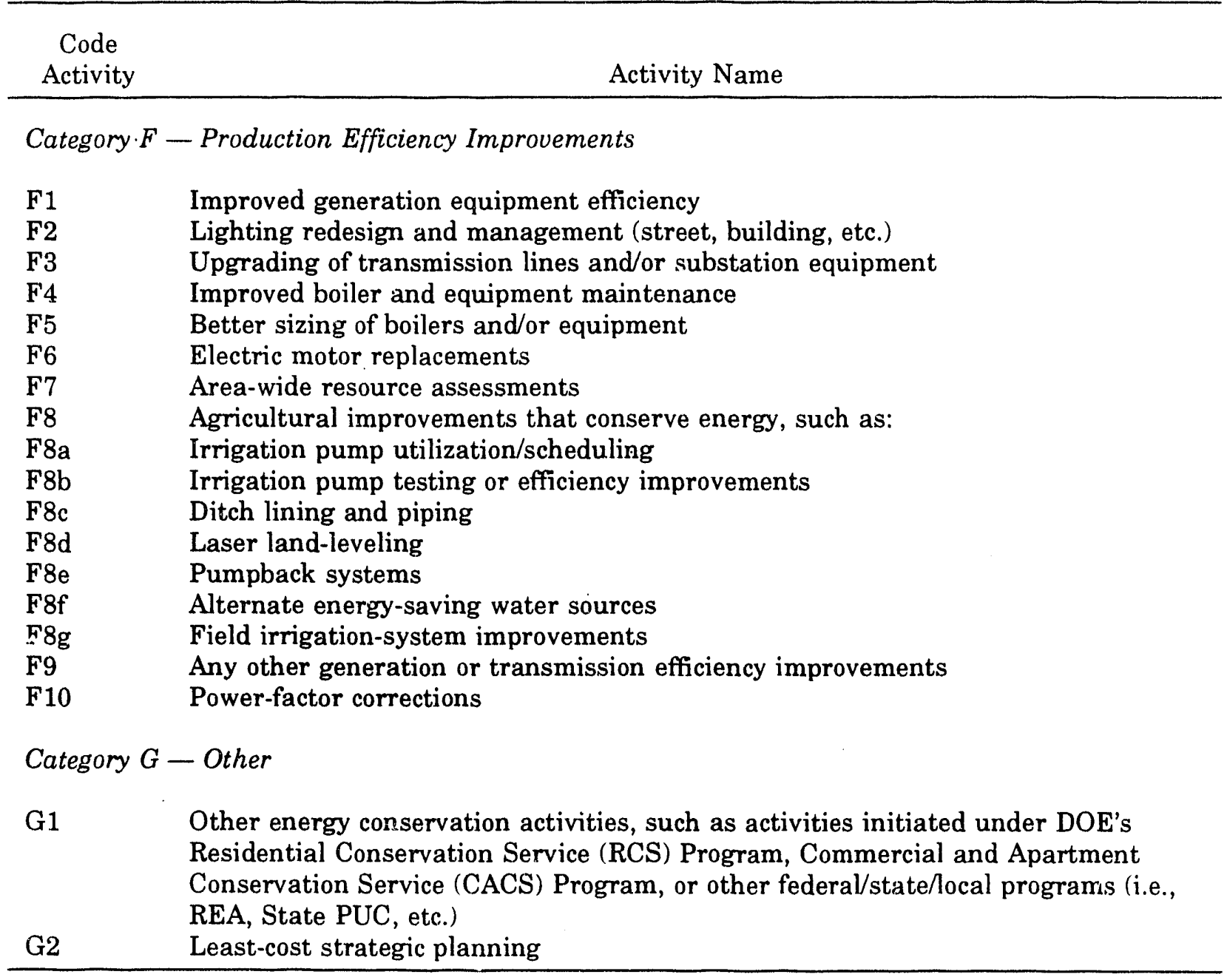

$V$ for voluntary in the Requirmt field. All the activities submitted to fulfill the requirement are listed as mandatory; all others are designated voluntary.

The Activity field gives a brief and descriptive title to the activity. A more in-depth discussion of the activity has been included in the Desc_fields described below. The activity title is often similar to the name associated with the activity code, although the two need not be identical.

Each utility is required to submit a goal for each activity. Western requests that the goals be measurable; that is, it asks that quantities be specified and results be quantifiable. However, not all activities have ruch goals. The goals that appear in the database (Goal) are those specified by the customers in the program submittals. The goals are to be used in the two-year program verifications submitted to evaluate the progress and effort of th: e utility in accomplishing its C\&RE goals. 
The Status field in the database reflects the state of the activity at the time of the submittal. The status is usually ongoing because most activities involve an action that is to be continual, but some are one-time activities that may be completed.

An extensive description of the activity represented by each record is given in the Desc_1 through Desc_6 fields. These six fields are long enough to provide for an in-depth explanation of the activity. All details relevant to C\&RE analysis have been included in these description fields. Because some activities, like energy audits, require very little discussion, little description will appear in the field. Other activities compel extended discussions. The six description fields permit 1,200 characters for the explanation of each activity. The descriptions presuppose a certain familiarity with the C\&RE-SLC program and terminology.

Western's customers can be classified into several different types. The Util_type field indicates a classification for each customer. Many customers are either a cooperative or owned and operated by a municipality. Several military bases and irrigation districts are also included in the database. In the Wapa_assn field, the database includes the name of any association of utilities to which the customer belongs. Some utilities deal directly with Western and do not belong to an association.

To determine the number of activities required by Western, the Gwh_sold field displays the amount of annual energy usage by the utility. Because energy usage varies from year to year within each individual utility, this field may also be useful in studies of energy usage patterns and the actual effects of the C\&RE programs on energy usage.

Each utility is required to submit an initial proposal for C\&RE activities. The year of this submittal is carried by the Init_plan field. The initial plan is important in noting the progress in individual utility programs. Two years after the initial plan, a program verification submittal is usually sent to Western. In other words, the set of entries in the database following an initial proposal will usually be a plan with a submittal year (Plan_year) dated two years later.

The last two fields in the database (Mand_act and Vol_act) are used to record the actual number of activities submitted that year by the utility in any planning-year submittal. The number of mandatory activities (Mand_act) will match the number of activities required by the amount of energy used by the utility. The number of voluntary activities (Vol_act) reflects the number of extra activities that the utility has chosen to pursue. 


\section{DATABASE APPLICATION}

The information contained in the C\&RE-SLC database can be used to provide a better understanding of programs undertaken by Western's customers. For instance, various statistics can be compiled from the data to summarize customer activities, as is done in Table 3. This table shows the distribution of customer programs since 1981. It lists the number of C\&RE programs by activity type for each of the plan years. The total number of programs increased significantly over the period. A more accurate representation of total customer programs is reflected by computing the two-year rolling average because customers are required to submit updates to their energy plans every two years. The two-year average has been calculated and is provided in Table 3 along with program totals. The data generally indicate an increase in the number of programs from year to year, with 1989 being the notable exception.

The frequency distribution of customer programs is shown in percentage terms at the bottom of Table 3. More than 50\% of the customer programs fall into category A, energy consumption efficiency programs, which involves the demand side of the market. The next highest category of customer activities is category F, production efficiency improvements, which relates to the supply side of the electricity market. Activities that target improvements in production efficiency make up approximately $30 \%$ of all activities.

TABLE 3 Frequency Distribution by Major Activity Type

\begin{tabular}{lrrrrrrrrrr}
\hline Category & 1982 & 1983 & 1984 & 1985 & 1986 & 1987 & 1988 & 1989 & 1990 & 1991 \\
\hline Raw count & & & & & & & & & & \\
& & & & & & & & & & \\
A & 2 & 16 & 10 & 18 & 40 & 99 & 121 & 61 & 141 & 132 \\
B & 0 & 0 & 2 & 5 & 2 & 15 & 10 & 4 & 10 & 18 \\
C & 0 & 1 & 1 & 2 & 4 & 9 & 23 & 6 & 28 & 22 \\
D & 0 & 0 & 0 & 0 & 4 & 5 & 2 & 0 & 3 & 1 \\
E & 0 & 0 & 0 & 1 & 3 & 4 & 8 & 1 & 7 & 6 \\
F & 0 & 0 & 5 & 11 & 25 & 68 & 48 & 36 & 67 & 69 \\
G & 0 & 0 & 0 & 0 & 0 & 1 & 0 & 0 & 3 & 0 \\
Total & 2 & 17 & 18 & 37 & 78 & 201 & 212 & 108 & 259 & 248 \\
& & & & & & & & & & \\
2-yr avg. & & 10 & 18 & 28 & 58 & 140 & 207 & 160 & 184 & 254 \\
& & & & & & & & & & \\
Percent of total & & & & & & & & & & \\
A & 100 & 94.1 & 55.6 & 48.6 & 51.3 & 49.3 & 57.1 & 56.5 & 54.4 & 53.2 \\
B & 0.0 & 0.0 & 11.1 & 13.5 & 2.6 & 7.5 & 4.7 & 3.7 & 3.9 & 7.3 \\
C & 0.0 & 5.9 & 5.6 & 5.4 & 5.1 & 4.5 & 10.8 & 5.6 & 10.8 & 8.9 \\
D & 0.0 & 0.0 & 0.0 & 0.0 & 5.1 & 2.5 & 0.9 & 0.0 & 1.2 & 0.4 \\
E & 0.0 & 0.0 & 0.0 & 2.7 & 3.8 & 2.0 & 3.8 & 0.9 & 2.7 & 2.4 \\
F & 0.0 & 0.0 & 27.8 & 29.7 & 32.1 & 33.8 & 22.6 & 33.3 & 25.9 & 27.8 \\
G & 0.0 & 0.0 & 0.0 & 0.0 & 0.0 & 0.5 & 0.0 & 0.0 & 1.2 & 0.0 \\
Total & 100 & 100.0 & 100.0 & 100.0 & 100.0 & 100.0 & 100.0 & 100.0 & 100.0 & 100.0 \\
\hline
\end{tabular}


The top three ranking customer activities within the energy consumption efficiency category were information dissemination, lighting conversions, and use of infrared heat detection equipment. For information dissemination, a search of the C\&RE-SLC database showed that Western's customers endeavor to increase conservation awareness through a variety of communication mechanisms, such as quarterly publications, bill stuffers, radio/newspaper advertisements, and conservation seminars. For the majority of customers that indicated an information dissemination activity, the stated goal was identified as promoting conservation rather than as a specific quantitative amount of energy savings. Similarly, for energy-efficient lighting conversions and use of infrared-heat-detection equipment, the utility goals typically were more indicative of a penetration rate rather than an energy savings.

On the supply side, Western's customers have focused on transmission and distribution, with nearly $40 \%$ of all production efficiency programs proposing equipment upgrades to lines and transformers (F3). The stated goal for the production categories is generally specific in terms of anticipated energy savings. For example, one F3 program indicated that replacing 103 miles of $69-\mathrm{kV}$ line with $138-\mathrm{kV}$ line and 11 miles of new line would bring system losses to less than $10 \%$. 


\section{AREAS FOR FURTHER RESEARCH}

The C\&RE-SLC database can contribute to the analysis of Western's C\&RE program in several ways. In addition to providing the foundation for ANL's research into C\&RE activities for the Electric Power Marketing Program EIS, the database offers Western's customers an easy means to examine other C\&RE programs that have been implemented by similar utilities.

Two topics that are not currently included in the C\&RE-SLC database would greatly enhance its usefulness and expand its capacity to support C\&RE research by Western, its customers, and outside parties. The first topic would be an evaluation of the historical program costs and energy savings associated with each C\&RE activity. No formal evaluation of the C\&RE program has been undertaken yet. Evaluations of each utility's C\&RE activities could provide the basis of more meaningful identification of the essential costs and benefits of such activities. The second area of further data development would be forecasting. Western's planning and the planning of its customers could be significantly improver if forecasts of energy and peak demand reductions from C\&RE activities were included ir a comparable fashion for all of Western's customers. 

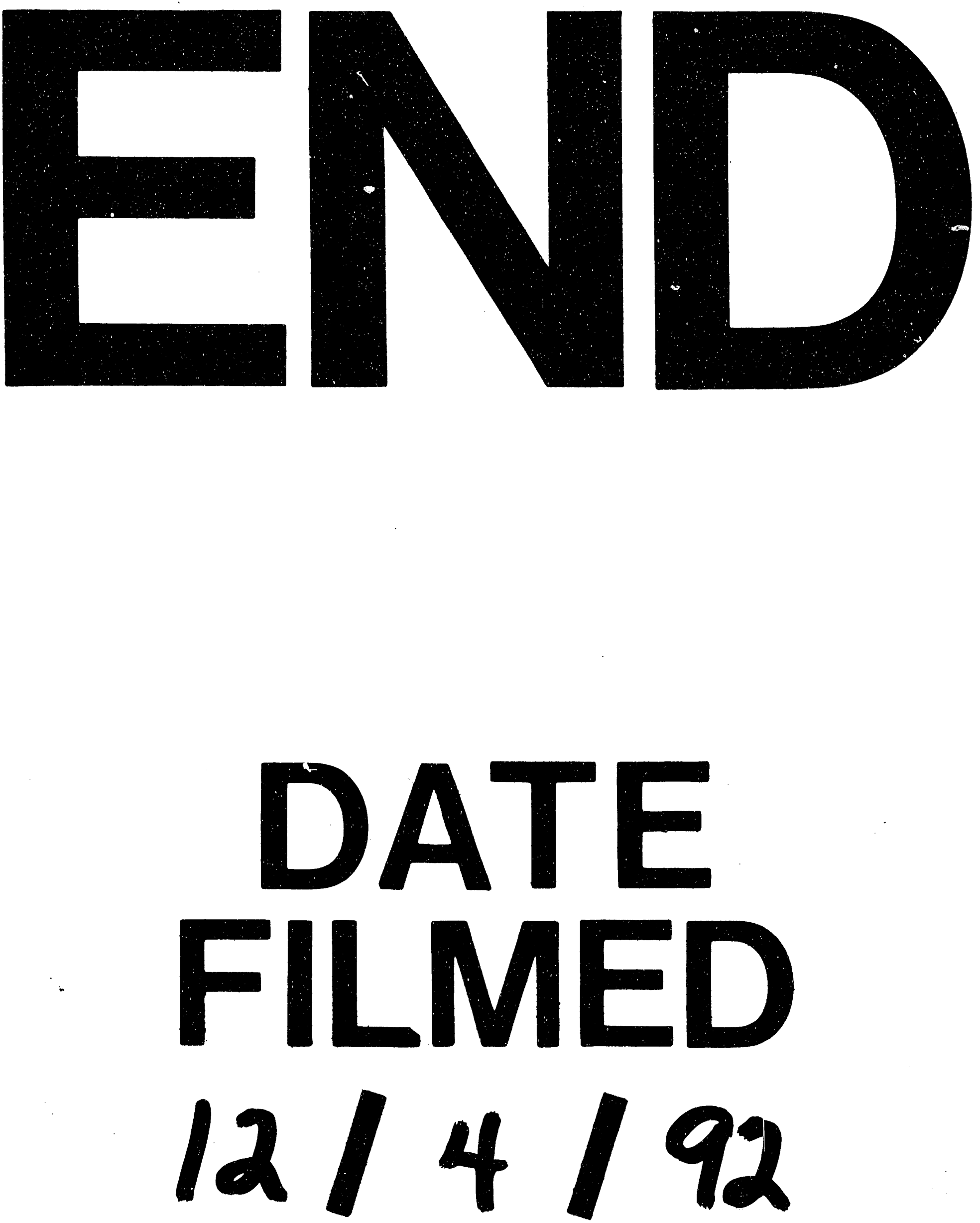
